\title{
Aa. Vv. «Annales Benjamin Constant», n. 38, 2013
}

\section{Catherine Thomas}

\section{(Q) OpenEdition}

\section{Journals}

Édition électronique

URL : http://journals.openedition.org/studifrancesi/1373

DOI : 10.4000/studifrancesi. 1373

ISSN : 2427-5856

\section{Éditeur}

Rosenberg \& Sellier

\section{Édition imprimée}

Date de publication : 1 décembre 2015

Pagination : 602

ISSN : 0039-2944

\section{Référence électronique}

Catherine Thomas, «Aa. Vv. «Annales Benjamin Constant», n. 38, 2013 », Studi Francesi [En ligne], 177 (LIX | III) | 2015, mis en ligne le 01 décembre 2015, consulté le 08 janvier 2021. URL : http:// journals.openedition.org/studifrancesi/1373 ; DOI : https://doi.org/10.4000/studifrancesi.1373

Ce document a été généré automatiquement le 8 janvier 2021.

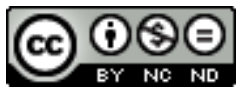

Studi Francesi è distribuita con Licenza Creative Commons Attribuzione - Non commerciale - Non opere derivate 4.0 Internazionale. 


\title{
Aa. Vv. «Annales Benjamin Constant», n. 38, 2013
}

\author{
Catherine Thomas
}

\section{RÉFÉRENCE}

Aa. Vv., «Annales Benjamin Constant», , pp. 212.

1 La première partie du volume, intitulée «Benjamin Constant et le groupe de Coppet», s'ouvre sur un article de Philippe LEJEUNE (pp. 9-34), qui se penche sur une figure oubliée de l'entourage de Benjamin Constant: Amélie Fabri, vainement courtisée par l'écrivain en 1803, essentiellement connue à travers le regard qu'il pose sur elle dans Germaine et Amélie, sa correspondance et son journal. Présentant et commentant pour la première fois le journal d'Amélie et les notes qu'elle apposa sur des billets d'invitation retrouvés, Philippe Lejeune redonne une voix à cette femme largement sous-estimée par Constant et explore les divers enjeux que prend sous sa plume l'écriture de soi. L'étude suivante, qui porte sur la réception du Commentaire sur l'ouvrage de Filangieri de Benjamin Constant, est la deuxième partie d'un article dont la première partie parut dans le numéro précédent (n. 37, 2012) des «Annales Benjamin Constant». Le chapitre V, rédigé par Antonio TRAMPUS (pp.35-62), présente le long compte rendu du Commentaire de Constant que Giovanni Valeri fit paraître dans la revue italienne «Antologia» en 1824, et propose une traduction française de ce compte rendu, qui constitue la première tentative de discussion de la pensée de l'écrivain en Italie. Le Chapitre VI, rédigé par Kurt KLOOCKE (pp. 62-78), présente un autre compte rendu, anonyme cette fois, paru dans la même revue en 1826, et qui offre une subtile analyse de la première traduction italienne du texte de Constant. Kurt Kloocke publie le compte rendu italien, dont la lecture est facilitée par un résumé succinct en français. Olivier MEUWLY (pp. 79-104) étudie ensuite avec clarté et précision les nombreuses annotations que La Harpe porta sur son exemplaire des Principes politiques de Constant, pour montrer qu'elles révèlent la parenté d'esprit des deux hommes et constituent une sorte de «fondement théorique 
du libéralisme laharpien», qui s'affirmera surtout dans les années 1820. Le numéro se poursuit par un volet intitulé «inédits»: Nora KöHLER (pp. 107-135) publie un manuscrit acquis par la Bibliothèque cantonale et universitaire de Lausanne en 2011; il s'agit d'une étude que le général Montesquiou consacra à la première brochure politique de Constant, sous le titre «Analyse et critique de l'ouvrage de Benjamin Constant intitulé De la force du gouvernement actuel de la France, et de la nécessité de s'y rallier». Françoise LAUNAY (pp. 137-154), dans un article intitulé Benjamin Constant et la rue d'Anjou, mystères dévoilés, fait état des résultats de ses recherches sur l'endroit précis où était domicilié Benjamin Constant rue d'Anjou-Saint-Honoré à Paris. Nous trouvons, dans la troisième partie de ce numéro («Euvres complètes de Benjamin Constant»), la publication par Paul DELBouille et Guillaume PoIsSon (pp. 157-161) d'un second exemplaire de l'engagement pris entre Benjamin Constant et Germaine de Staël au début de leur relation, dont le premier exemplaire, aujourd'hui inaccessible aux chercheurs, se trouve dans les archives du château de Broglie; puis Paul Delbouille et Frédéric JAUnin (pp. 163-168) dressent l'inventaire des éditions d'Adolphe depuis 1885, date à laquelle s'achève le relevé des œuvres publiées de Constant par C.P.Courtney. Enfin Paul DELbouille (pp. 169-170) fait le point sur la publication des Cuvres Complètes de Benjamin Constant, et le volume s'achève sur une série de comptes rendus d'ouvrages relatifs à Benjamin Constant et au groupe de Coppet. 